\title{
Строение крон древесных растений умеренной зоны на примере Acer negundo и Ulmus glabra
}

\author{
(C) И.С. Антонова, В.А. Барт \\ Санкт-Петербургский государственный университет, г. Санкт-Петербург, Россия \\ e-mail:ulmaceae@mail.ru
}

\begin{abstract}
На примере крон Acer negundo и Ulmus glabra, исследованных в разных возрастных состояниях и в разных точках ареала, предложена модель зональности побега. Зональность основана на связях процессов развития побега с другими пространственно-временными структурными единицами кроны (двулетние побеговые системы, эпсион и др.). Задержка развития рассматривается как альтернатива (торможение, латентная стадия) процессов старения побега. Модель использует математический аппарат частичного обращения функций, оценку параметров ковариационной функции комплексного марковского нормального стационарного процесса по его многомерным реализациям.
\end{abstract}

Ключевы е слова: крона, побеговые системы, зональность побега, принцип отражений, частично-обратные функции.

Изучение строения крон представляет сложную и до настоящего времени слабо разработанную проблему. С античных времен крона дерева представляется динамичной системой, чутко реагирующей на окружающую среду. В связи с этим, описание крон исторически развивалось по нескольким направлениям. Ботаники описывали крону, сравнивая ее с определенной трехмерной геометрической фигурой - цилиндром, овалом, конусом и т. д., или с понятной бытовой пространственной формой - зонтиком, чашей и пр. Нередко описание формы заканчивается универсальной и малозначимой формулировкой «крона неправильной формы». Биологи и математики, пытаясь описать крону, шли по пути моделирования, и в этом направлении накоплен огромный опыт, касающийся моделирования отдельно стоящего дерева (Guedon et al., 2001; Galitskii, 2004) и его ветвей (Wilson, 1989, 1993; Costes, Guédon, 2002; Galitskii, 2013;), сообществ деревьев и их связи с произрастанием в определенных условиях (Maillette, 1982; Gavrikov, Khlebopros, 2013). Эти интересные и убедительные исследования используют разнообразные математические аппараты и подходы для описания структуры дерева: дифференциальные уравнения, матрицы, геометрический подход, симуляцию и имитацию внешнего вида, фракталы и L-системы (Prusinkiewicz, Lindenmayer, 2012).

Чаще всего модели опираются на наблюдаемый рост побега и высоту ствола дерева. Построение единой динамической системы, представляющей крону как комплекс соподчиненных пространственно-временных единиц, позволяет по-новому подойти к описанию кроны и представляется актуальной задачей биоморфологии. Создание комплекса признаков, характеризующего крону как единую динамическую систему структуры дерева, нуждается, на наш взгляд, в привлечении адекватного математического аппарата, требует объединения подробных морфологических описаний и длительных многолетних наблюдений онтогенеза.

Применение пространственно-временной системы единиц к описанию кроны приводит к необходимости введения нескольких пространственных и временных шкал, связанных между собой. Особого внимания заслуживает проблема выбора математического аппарата описания этой связи, в простейшем случае, побега и двулетней побеговой системы (ДПС).

Целью работы является выяснение логической структуры связей побега с другими пространственно-временными единицами кроны дерева, в частности, с двулетней побеговой системой.

\section{М а те ри алы и ме т оды}

Основным материалом для данной статьи явились ДПС и кроны Acer negundo L. (База данных ANTREES, свидетельство о государственной регистрации баз данных №2016621088 от 9 августа 2016 года). Были исследованы 34 кроны с описанием 
следующих признаков: растительное сообщество, из которого взято дерево, возрастное состояние, высота и диаметр ствола, год появления каждого побега, длины всех побегов и длины междоузлий побегов основных осей, количество листьев на всех побегах дерева, углы ответвления побегов. Для 500 ДПС были измерены длины всех побегов, и длины междоузлий осевых побегов, количество листьев на всех побегах, углы ответвления побегов.

Со 100 деревьев подроста Ulmus glabra Huds. в естественной дубраве заповедника Белогорье были собраны 200 ДПС. С каждого дерева было взято по две ДПС: ростовая на оси второго порядка (массив Б) и основная на оси третьего порядка (массив А). Ростовая ДПС всегда собиралась на верхушке основной оси крупной ветви. У всех ДПС были измерены длины всех побегов, количество и длина междоузлий материнского побега, количество листьев на всех побегах, углы отклонения боковых побегов от материнского.

На территории европейской части России и ближнего зарубежья более 30 лет изучается строение кроны древесных растений умеренной зоны в естественных насаждениях и интродукции (Antonova, Fatyanova, 2016). Исследованы растения более чем 35 родов различных семейств. Для большого количества видов изучение проходило в разных возрастных состояниях. Был предложен метод выделения ДПС и их классификация (Antonova, 2008; Antonova et al., 2012; Antonova, Fatyanova, 2016), а также иерархия пространственно- временных единиц строения кроны (побег, ДПС, эпсион, ветвь от ствола, крона) от метамера до многокронового организма (Рис. 1).

Перечислим основные свойства каждой из единиц.

Побег дерева рассматривается как самонастраивающаяся более или менее целостная система, обладающая определенной автономностью и свойством полярности. Он происходит из единой меристемы, имеет симметрию, в значительной мере определяемую работой конуса нарастания, характеризуется определенной длиной, несет некоторое количество боковых листовых органов, образует некоторое количество пазушных почек разного строения, имеет свойство ветвления, проявляющееся большей частью на второй год жизни.

Количество разворачивающихся на нем почек определяется положением побега и окружением его другими побегами в системе ветви и кроны, подобно тому, как дифференциация и специализация растительной клетки зависит от положения относительно соседних клеток и взаимодействия с ними в виде натяжения мембран.

Заложение листовых органов при формировании почки, зимняя пауза, разворачивание и рост весной, период существования с зелеными листьями, разворачивание боковых побегов - это все отрезки временной составляющей жизни побега, и они не могут быть игнорированы при работе с ним. Годичный побег (Рис. 1.1) - минимальная элементарная единица в строении кроны дерева
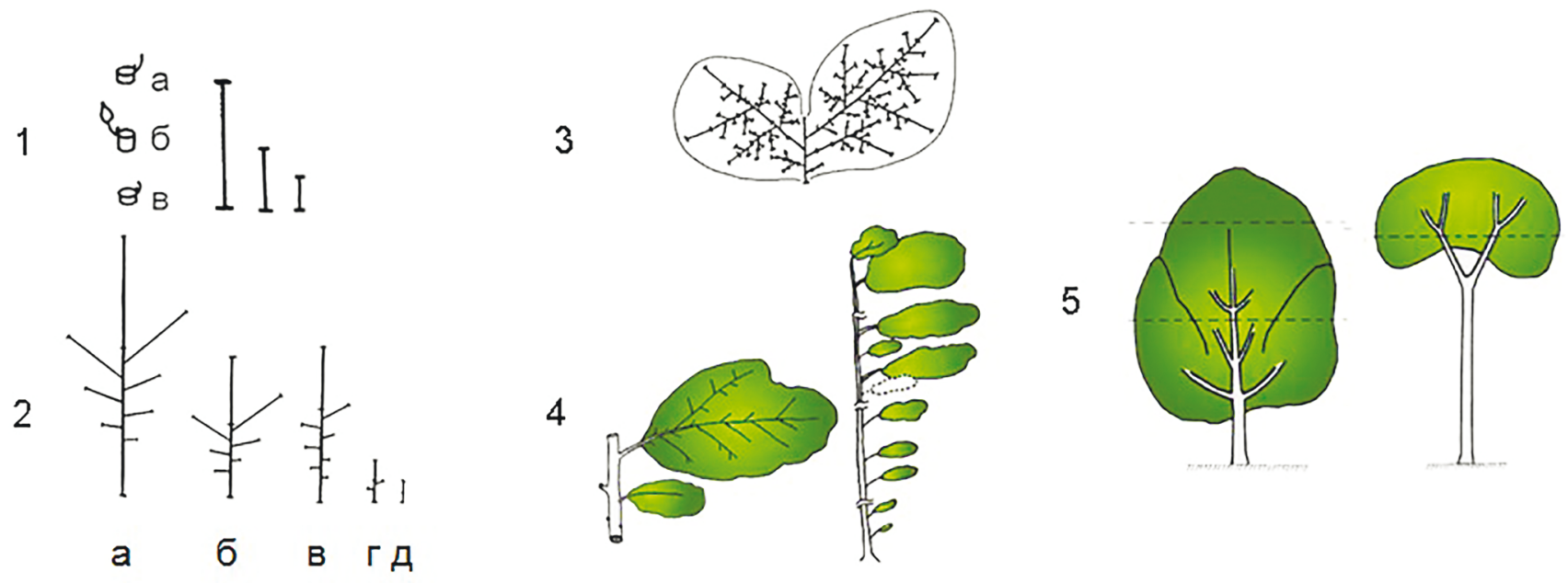

Рисунок 1. Уровни иерархии строения кроны. 1 - побеги разной длины, состоящие из метамеров: а - в верхушечной части побега, б - в средней части, в - нижней части побега; 2 - двулетние побеговые системы: а - ростовые, б - основные, в - узкоконтурные, г - ветвящиеся заполняющие, д - не ветвящиеся заполняющие; 3 - эпсион; 4 - ветви от ствола; 5 - кроны: у теневыносливых растений (3 зоны в кроне) и у светолюбивых (2 зоны)

Figure 1. Hierarchy levels of the crown structure. 1 - shoots of different length, consisting of metamers: a - in the apical part of the shoot, $\sigma$ - in the middle part, в - in the basal part of the shoot; 2 - biennial shoot systems (BSS): a - growth, $\sigma$ - basic, B - narrow contour, $\Gamma$ - branching filling, д - non-branching filling; 3 - epsion; 4 - branches from the trunk; 5 - crowns: in shade-tolerant plants ( 3 zones in the crown) and in photophilous plants ( 2 zones) 
(отчетливо выделяемая и единая в функциональном отношении). Качество побегов определяется последовательностью метамеров, в том числе свойствами боковых почек, формируемых в этих метамерах (Antonova et al., 2012). В основе выделения нами годичного побега лежат представления И.А. Грудзинской (Grudzinskaya, 1960) об элементарном побеге.

Следующим после побега уровнем в иерархии кроны является двулетняя побеговая система (ДПС).

ДПС представляет собой материнский побег и развившиеся из его пазушных почек боковые побеги. Базовые характеристики двулетней побеговой системы: количественный и качественный состав боковых побегов (Рис. 1.2). Она также обладает определенной геометрией, размерными соотношениями боковых побегов между собой и с материнским побегом, углами ответвления боковых побегов от материнского, проявлениями акро-, мезо- или базитонии, функциональными особенностями боковых побегов, что связано с выполняемыми ею функциями, и позволяет легко идентифицировать ее в кроне. Набор ДПС определяется программой развития вида и различен для разных онтогенетических состояний (Antonova, Fatyanova, 2016).

Эпсион (термин по Antonova et al., 2012) (Рис. 1.3) - динамическая единица строения кроны. Она представляет собой результат полного развития пространственной структуры, основанием которой является ДПС. В течение нескольких (вплоть до десятка) лет побеги разных порядков от определенной оси (материнского побега) последовательно заполняют пространство в окружении этой оси. Одновременно с ростом в периферической части эпсиона внутренняя часть его побегов постепенно отмирает снизу-вверх. Особенности строения эпсиона определяют узнаваемый рисунок расположения побегов в кроне у каждого вида. В кроне присутствуют качественно различные эпсионы, в основе которых лежат материнские побеги разных ДПС.

Ветвь от ствола (Рис. 1.4) - наиболее крупная классификационная единица в составе кроны, единое в морфогенетическом смысле образование, состоящее из побегов, которые происходят из одной меристемы материнского побега. Ветви расположены в кроне ярусами (Shitt, Metlitskii, 1940). Нижние, средние и верхние ветви дерева формируются в разных онтогенетических состояниях, имеют различия в составе ДПС. Близкое расположение ветвей на стволе не означает, что они одинаковые. Значимо не только их расположение на разной высоте на стволе и по секторам кроны, но и образование в разное время.

Крона (Рис. 1.5) описывается как комплекс ветвей и ствола. Свойства каждой ветви зависят от того, в какой части ствола она образуется, но на более высоком уровне регуляции все ветви функционируют совместно. Крона, состоящая из ветвей от ствола разного положения, существует как единая система, хотя в ней и могут быть выделены элементы разных иерархических уровней (Antonova, Fatyanova, 2016).

Каждую из единиц можно рассматривать как программу развития. Вложенные одна в другую, они создают последовательный ход онтогенеза. Реализацияоднойпрограммызапускаетследующую, создавая нелинейную систему взаимодействий.

Из крон молодых растений четырех видов рода Acer L. (A. platanoides L., A. cissifolium (Sieb. etZucc.) K. Koch, A. tegmentosum Maxim., A. henryi Pax.), используя вышеназванные свойства, выделили ДПС. Затем, смешав эти ДПС в одну выборку и применив методы многомерной статистики, разделили эти побеговые системы по двум простым морфологическим признакам: длине материнского побега и длине максимального бокового побега (Antonova et al., 2016; Antonova, Bart, 2016). Это анализ, в частности, подтверждает существование как общих, так и характерных свойств ДПС у каждого из изученных видов.

Полученная типизация совпадает с проведенным ранее морфологическим разделением ДПС по большому комплексу линейных, угловых, временных и функциональных параметров. Было показано, что всего лишь два признака определяют трехмерную геометрию ДПС исследованных видов рода Acer. Таким образом, трехмерная ДПС оказывается принципиально двумерной.

Возможность описания модели связи побега и ДПС двумя независимыми параметрами делает удобным привлечение аппарата случайных процессов. Так, в известной работе (Arato et al., 1962), были предложены оценки параметров комплексного марковского нормального стационарного (КМНC) процесса по его реализациям, позднее А.Г. Бартом (Bart, 2003) описана серия моделей кривых продолжительности жизни, основанных на процессах такого типа.

Ковариационная функция КМНС процесса имеет вид (Arato et al., 1962; Bart, 2003; Alekseeva, 2012):

$$
S(t)=\sigma^{2} \exp (-\eta t) \cos \tau t, t>0,
$$

где вещественные параметры $\sigma^{2}, \eta$ и $\tau$ будут интерпретированы ниже.

Для получения модельной кривой $F(t)$ применяется двойное частичное (обобщенное) обращение функции S с параметром частичности $\gamma$ (Bart, 2003; Alekseeva, 2012):

$$
F_{\gamma}(t)=\gamma \pi \mathrm{S}\left(\mathrm{t}-\mathrm{T}_{0}\right)
$$




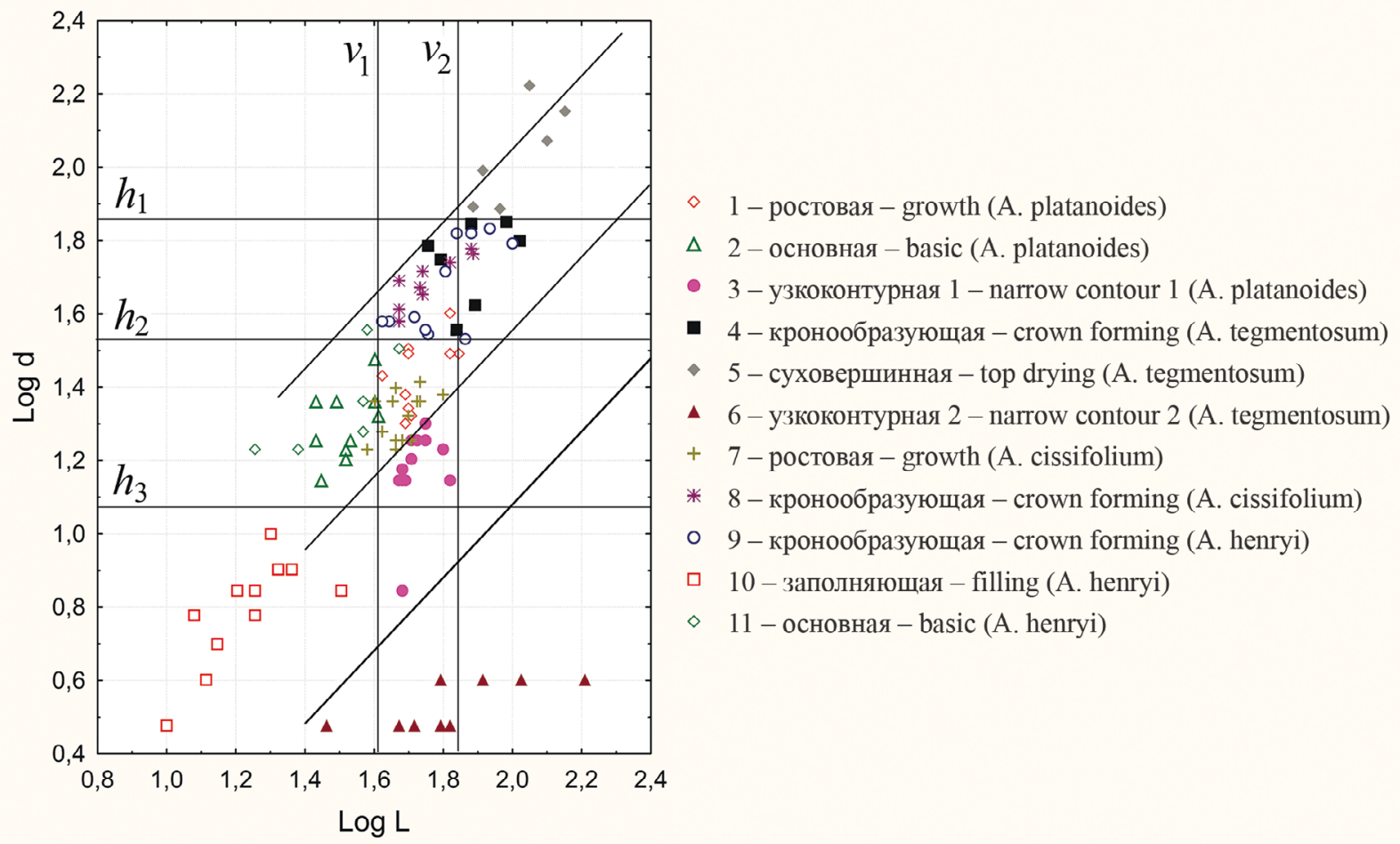

Рисунок 2. Совместная диаграмма рассеяния признаков длины материнского побега L и максимальной длины d бокового побега ДПС 4 видов рода Acer (разметка осей в масштабах десятичного логарифма, мм)

Figure 2. A joint diagram of the signs scattering of the mother shoot length $\mathrm{L}$ and the maximum length $\mathrm{d}$ of the lateral shoot of the BSS of 4 species of Acer (marking the axes in the scale of the decimal logarithm, mm)

На рисунке 3 приведена теоретическая модель кривой продолжительности жизни макропобега («кривая саногенеза» (Bart, 2003)) для $\gamma=0, \gamma=1$ $u \quad \gamma=0,5$. Точное определение макропобега будет дано ниже, а здесь скажем, что в нашей модели она будет иметь смысл теоретической кривой оценки вероятности дорастания побега на дереве до момента $t$. Параметр $\gamma$ имеет смысл стратегии,

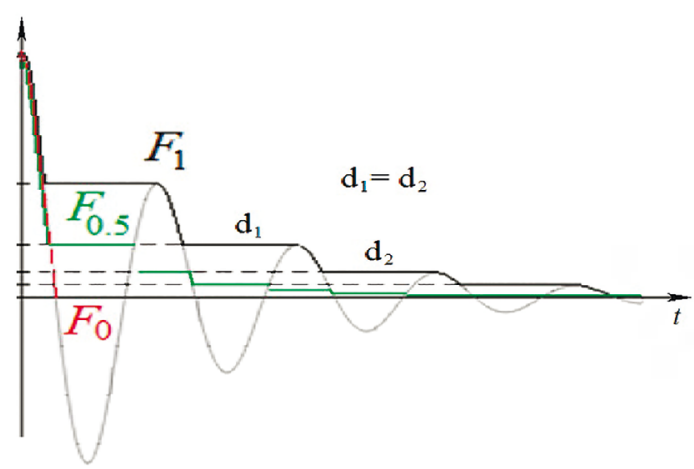

Рисунок 3. Теоретическая модель кривой продолжительности жизни макропобега (кривая саногенеза).

F0 - максимально быстрое старение, F1 - максимально длительное омоложение, F0,5 - промежуточный вариант с $(\mathrm{m}=2)$

Figure 3. Theoretical model of the lifetime curve of the macroshoot (curve of sanogenesis).

F0 - maximally rapid aging, F1 - maximally long rejuvenation, F0.5 - intermediate version with $(\mathrm{m}=2)$ с которой побег осуществляет свое развитие. При этом $\mathrm{F}_{0}$ - максимально быстрое старение, $\mathrm{F}_{1}$ - максимально длительное омоложение, $\mathrm{F}_{0,5}$ - промежуточный вариант.

В монографии А.Г. Барта (Bart, 2003) вводится понятие устойчивых регуляций в системе, и, в частности, показано, что только выбор параметра $\gamma=1 / m$, где $m$ - натуральное число, для устойчивости процесса необходимо, чтобы распределение значений $F(j), j=1, \ldots, m$, было обобщенным геометрическим распределением:

$$
F(j \mid q, \gamma)=q^{\gamma_{j}}-q^{\gamma_{j+1}}, \gamma_{j}=\left[\frac{j}{\bar{m}}\right] .
$$

В нашей модели это соответствует устойчивости процесса управления ростом побега со стороны всего дерева.

\section{Результаты иобсуждени е}

Большинство математических моделей, применяемых для формализаций биологических процессов, в основе имеют готовые модули, созданные и опробованные на практике в физике, механике, химии, информатике. Биологические принципы часто оказываются не заложены в исходный формализм и отдаются на откуп симуляционной части биологической модели или апробации последней. Более того, даже язык математического аппарата модели был сформирован под влиянием 
задач физики и механики и подразумевает, что биологический процесс происходит в одном «лабораторном» времени наблюдателя. Тем не менее, основным исходным понятием в биологии является онтогенез, который подразумевает, что развитие организма происходит в своем, внутреннем, времени. То есть изначально существуют два времени, которые необходимо учесть при построении модели.

При реконструкции процессов, формирующих крону дерева и ее части, выделим те принципы, которые исходно должны быть учтены в ее основном математическом выражении. Наиболее существенными, на наш взгляд, являются следующие 4 принципа:

\section{Принции отражений.}

Взаимодействие между структурными единицами кроны дерева характеризуются определённой программной жесткостью. Н.П. Кренке (Kren$\mathrm{ke}, 1940)$ писал о процессах старения и омоложения в развитии побега, идущих одновременно. В то время как активизируется один процесс, другой находится в пассивной («латентной») стадии.

Остановимся на формулировке принципа, предложенной А.Г. Бартом с соавторами (Bart et al., 1993): в жестко зарегулированной системе реализации двух процессов - воздействия на систему и ответного ее противодействия - являются (возможно, обобщенными) взаимно-обратными функциями.

Сопоставление времени действия и времени ожидания действия в общем виде известно в теории случайных процессов (Dynkin, 1963; Feller, 1984). Из практических соображений, связанных с этим зеркалом, Р.А. Фишер (Fisher, 1956) ввел фидуциальный подход в статистике. Практическое моделирование таких процессов представлено А.Г. Бартом (Bart, 2003) на основе процедуры обобщенного обращения функций. Один из описанных им подходов мы возьмем за основу предлагаемой нами модели.

\section{Основная программа развития кроны дерева.}

Побегу и кроне в целом присуща программа максимального развития, и ее реализация происходит при взаимодействии двух процессов: омоложения и старения. Н.П. Кренке (Krenke, 1940) особо отмечал, что итоговое развитие побега есть «результат борьбы и единства его старения и омоложения». Понятия борьбы и единства означают, что существуют и другие причины, оказывающие влияние как на старение, так и на омоложение, и управляющие развитием побега. Как установлено в наши дни такой причиной и является общая генетическая (в широком смысле) программа развития побега.

Крона, состоящая из огромного количества побегов разной величины, заполняет огромное пространство. Заполнение пространства заставляет организм постоянно решать проблему перехода пространства во время и обратно. Здесь мы имеем в виду то, что развитие длинного побега позволяет за короткое время захватить очень большое пространство, которое затем осваивают многочисленные мелкие боковые побеги, развивающиеся на нем.

При развитии эпсиона хорошо видно, как ежегодно образующиеся боковые побеги становятся все меньше в размерах. С другой стороны, в пределах кроны организму необходимо размещать достаточное количество листовых пластинок. Образуя мелкие побеги, ветви, не форсируя события, могут развиваться и заполнять пространство длительное время. Значительной трудностью в описании процесса формирования кроны является параллельное протекание процессов разного уровня, причем каждый уровень строения кроны живет в своем времени (Рис. 4, 5).

Рисунок 5 иллюстрирует распад первичных эпсионов на Ulmus laevis Pall., сопутствующий появлению новых. Это приводит к «дроблению времени» - появлению нескольких «новых времен», в каждом из которых происходит программный процесс появления новых эпсионов и исчезновение старых.

Принции:задержкаразвитиякакединственная альтернатива смерти.

Развитие побега проходит в течение вегетационного сезона, имеет большое количество этапов, и, как следствие, некоторое количество морфологически выраженных зон. Иными словами, иерархические единицы кроны более высокого уровня не могут усовершенствовать сложившуюся веками программу развития более низких единиц. Старшие единицы могут только тормозить развитие определенных фаз в реализации этой программы. Получающиеся при этом побеги будут мелкими и с частично исчезнувшими зонами (по отношению к максимальной программе их развития). Формирование таких побегов позволяет растению приспособиться к жизни в неблагоприятных условиях, например, при нехватке ресурсов. Организм в целом не погибает, справляясь с трудностями среды.

С позиций омоложения процесс выглядит таким образом: торможение процесса старения есть успешное развитие нового побега, нужного старшей единице строения кроны. Это приводит к развитию длинных, хорошо обеспеченных водой, минеральными солями и органикой побегов, большой величины.

Таким образом, в жизни побега присутствуют 


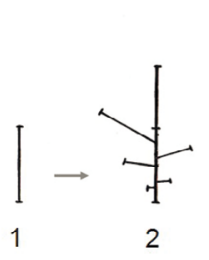

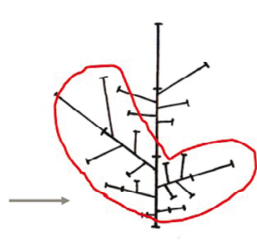

3
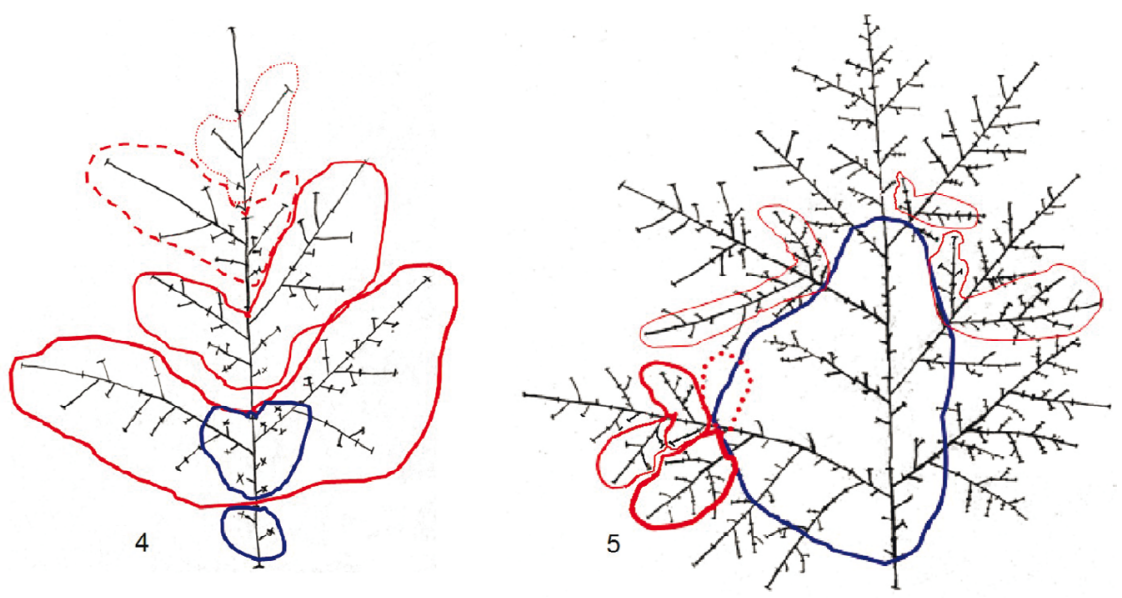

Рисунок 4. Развитие побега в двулетнюю побеговую систему, эпсион и ветвь от ствола на примере Tilia cordata Mill. 1 - побег, 2 - ДПС ростового типа, 3 - эпсион (в красном контуре), 4 - ветвь от ствола (красный контур - последовательность эпсионов молодой ветви, синий - начавшийся процесс отмирания мелких побегов), 5 - ветвь от ствола зрелого дерева (красный контур - эпсионы, образовавшиеся на осях второго и третьего порядка; синий контур - процесс отмирания мелких побегов)

Figure 4. Development of shoot into a BSS, epsion and branch from the trunk by the example of Tilia cordata Mill.

1 - shoot, 2 - BSS of growth type, 3 - epsion (in the red contour), 4 - branch from the trunk (the red contour - sequence of young branch epsions, the blue contour - dying off of small shoots), 5 - branch from the trunk of mature tree (the red contour - epsions formed on the second and third order axes, the blue contour - the process of dying off small shoots)

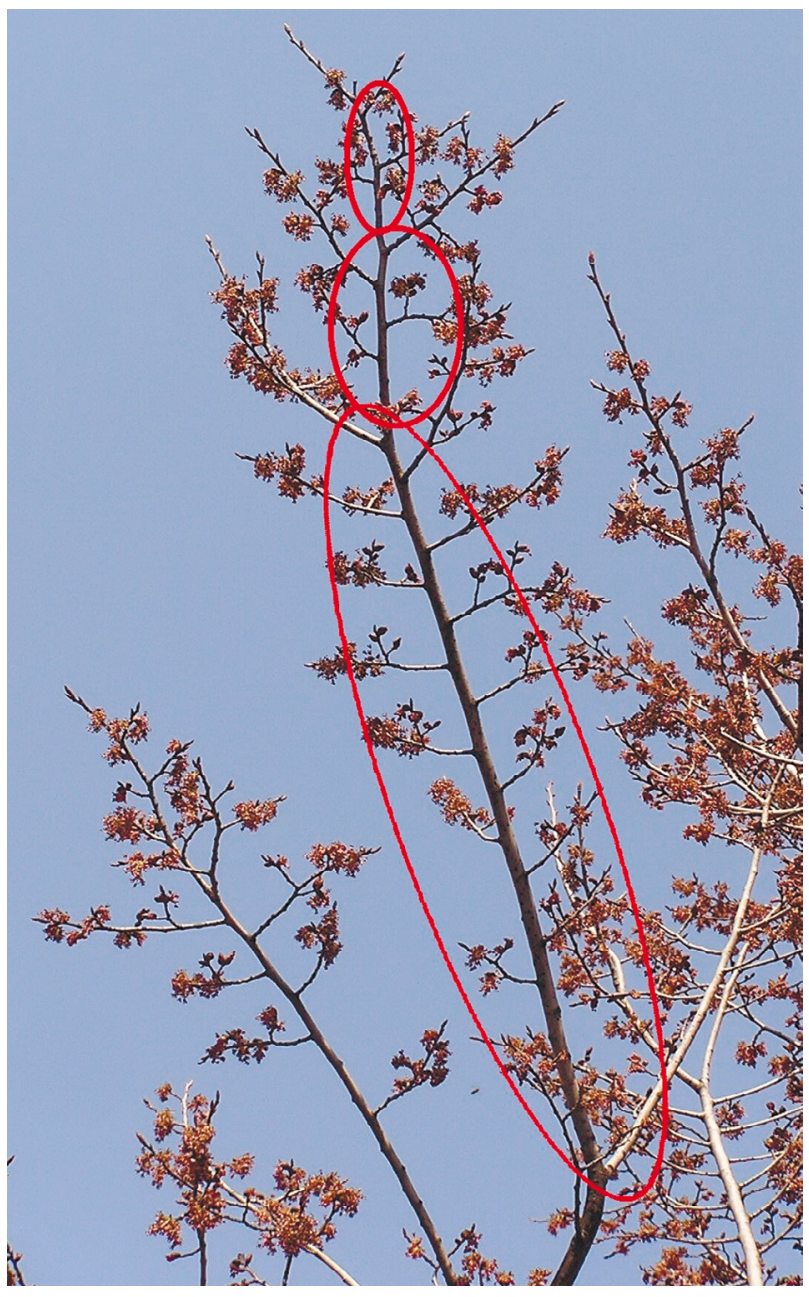

Рисунок 5. Выделены первичные эпсионы оси U. laevis Figure 5. Selected primary epsions of the axis of $U$. laevis два разнонаправленных временных процесса, два времени. Один из них естественно считать в «прямом» времени - это развитие с точки зрения наблюдателя, а второй - в обратном времени времени ожидания этапов. Подобный взгляд разработан в математической теории случайных процессов (Dynkin, 1963; Feller, 1984).

Управляющая и подчиненные структурные единицы кроны порождают собственное время взаимодействия, в котором омоложение и старение у каждой из них идут в противоположном направлении по отношению друг к другу. Так, например, появление новых побегов на дереве омолаживает дерево целиком, так как многие функции начинают выполнять более молодые побеги. Старые же побеги оказываются функционально старше, что и означает, что каждый побег в отдельности при этом стареет.

Вместе с принципом основной программы развития структурной единицы принцип задержки развития позволяет нам считать, что вариант развития ДПС (или его материнского побега) близкий к основному программному варианту реализуется на наиболее развитых ростовых ДПС.

Зеркало начала и конца роста побега.

Зеркальная несимметричность физического мира появилась в физике после статьи T.D. Lee and C.N. Yang (1956). На сегодняшний день в физике насчитывают пять основных типов зеркал (Novozhilov, 1972), по которым классифицируют элементарные частицы. Их проявления связанны 
с физическими микро- или макромиром.

В биологии зеркала намного ближе к исследователю. Поясним это на примере развития побега.

Полярность побега упоминают, когда хотят подчеркнуть морфо-физиологическую асимметрию его концов. В то же время, сам факт уменьшения длин междоузлий, других метамеров и размеров различных зон от середины побега к его краям не вызывает сомнений. Возникают две естественные системы кодирования междоузлий на побеге: от начала и от конца. Последняя, например, играет важную роль при описании типов ДПС различных видов деревьев (Antonova et al., 2012). Статистический «макропобег» (то есть набор актуальных свойств, характерных для всех побегов выделенного массива данных) обладает двумя противоположными представлениями, которые часто характеризуют его по-разному. Так естественный процесс старения побега удобнее рассматривать с точки зрения первых стадий формирования побегов и их кластеризации (Antonova, Bart, 2015), то есть там, где этот процесс наиболее интенсивен. Процесс омоложения по Н.П. Кренке (Krenke, 1940) отчетливее проявляется при совмещении последних междоузлий побегов (Antonova, Bart, 2015), из которых, например, у исследуемых видов растут наиболее развитые боковые побеги.

По-видимому, подобные «зеркала» в кодировке метрических признаков свойственны любой пространственно-временной единице кроны дерева, в частности, и ей самой. Так, крона в целом у $A$. negundo формируется на генеративной стадии G1, когда уже дерево имеет наиболее полный состав всех типов структурных единиц.

Для составления базы данных характеристик побегов всей кроны или ее части удобно использовать две противоположные кодировки побегов в кроне.

Обе кодировки сопоставляют произвольному побегу код, однозначно определяющий его положение на дереве, не зависящее от порядка общего списка имен и позволяющее представлять данные в виде прямоугольной таблицы в реляционной базе данных.

Благодаря понятию порядка ветвления все побеги на дереве можно разделить на «линейные» и «боковые».

Первая из кодировок (Antonova, Bart, 2015)-назовем ее кодировкой снизу - строит код следующим образом. Если двигаться от ствола, то к побегу по дереву ведет единственный кратчайший путь. Первое поле в имени побега есть число, равное количеству лет дерева, которое придется «пройти» по стволу до первого «поворота» на боковой побег. Второе поле занимает буква, лучше - русского алфавита, где их 33 (или хотя бы 31), обозначающая уровень (междоузлие) на побеге, начиная сверху, на котором произошел поворот. Вследствие супротивного расположения побегов на $A$. negundo повернуть можно только направо или налево по ходу движения (Рис. 6). Этим направлениям соответствует знак третьего поля имени. Само третье поле содержит число лет «хода» до поворота на следующий боковой побег и так далее.

Сумма чисел в имени без учета знака равна возрасту побега в годах, начиная с «первого» года, выбранного на стволе.

Для построения имени побега на деревьях с несупротивным расположением боковых побегов, возможно, придется завести дополнительные поля между буквами и числами для конкретизации поворотов.

Для альтернативной кодировки, которую естественно назвать кодировкой сверху, для всех осей дерева кроме ствола удобно ввести понятие материнского побега оси. Оно обозначает побег, боковой узел которого является основанием данной оси.

Первым символом такого кода является знак плюс или минус в зависимости от того, с какой стороны ось подходит к своему материнскому побегу. Для побега в стволе дерева это поле может быть пропущено или всегда выбрано «плюсом». Второе поле кода - число, равное возрасту побега в годах (текущий год принимается за 1). Затем идет поле с буквой, символизирующей уровень оси побега, то есть уровень на последнем предке побега, на котором изменилась ось, и соответствующий основанию этой оси. Знак третьего поля соответствует направлениям поворота оси: например, налево всегда - минус, а направо - плюс. Само третье поле содержит возраст упомянутого предка, несущем основание оси побега. И так далее до ствола дерева.

Для U. glabra, имеющего очередное плагиотропное расположение побегов, кодировка не меняется. При этом, сколько бы ни было на побеге боковых побегов, при буквах с четными номерами в алфавите всегда будут стоять плюсы, а при нечетных - минусы, или наоборот, в зависимости от конкретного побега.

Последовательность цифр в таком коде побега возрастает, возраст побега равен первому числу кода.

Такая кодировка, использующая нумерацию «сверху», зеркальная к предыдущей «снизу», более удобна при практическом сборе побегов, так как обычно проще выяснить возраст конкретного побега, чем количество лет, отделяющих его от основания дерева. Да и сама нумерация не зависит ни от выбора начального побега в основании, ни от возраста всего дерева и позволяет единообразно кодировать как целые деревья, так и их блоки: ветви от ствола, элементы кружева кроны и другие. 
В обоих способах кодирования общее количество букв в итоговом имени побега (то есть «поворотов») равны порядку ветвления побега.

Напомним, что кодировка «снизу» начиналась с выбора «первого», начального побега в основании дерева. Если такой побег в основании выбран, или, что то же самое, выбран максимальный возраст ствола, то обе зеркальные кодировки какого-либо фиксированного побега на дереве легко могут быть переписаны одна в другую.

Например, побегу, представленному на схематическом рисунке 6 (выделен красным), соответствует нижний код: «1Б+1А-2Г-2» и верхний: «-2Г+4А-6Б $+7 »$.

Таким образом, мы имеем зеркало в кроне: верхняя и нижняя кодировка. Это аналог прямого и обратного времени, соответствующего двойственным процессам: например, процессу образования узла на побеге и процессу ожидания этого события.

Рассмотрим побег как процесс полета летательного аппарата (самолета, дрона). В этом процессе есть начало и конец - то есть взлет и посадка. Это две обязательные стадии процесса. У побега они соответствуют этапу инициации заложения почки, из которой разовьется побег, и этапу, предшествующему заложению почки следующего года, то есть окончанию роста побега.

Имея в виду, что побегу присуща программа максимального развития, мы можем сказать, что ее реализация происходит во взаимодействии двух процессов: омоложения и старения Кренке (Krenke, 1940).

Итак, у каждого побега взаимодействуют три причины, управляющих его ростом: программа развития, старение, омоложение - на которые оказывает существенное влияние окружающая среда.

В общем виде дерево

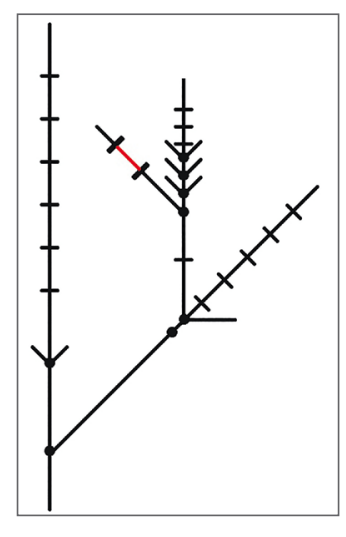
имеет медленное начало развития кроны на стволе. В любом случае в начале жизни кроны побегов мало. Затем развитие приводит к появлению более длинных, но соотношение длинных побегов к общему числу побегов, образующихся за год, в этот период максимально по отношению к другим периодам в жизни

Рисунок 6. Схема зеркальной кодировки побега в кроне дерева. Кружки соответствуют уровню бокового побега на материнском, а отрезки - границам побегов

Figure 6. Scheme of the mirror coding of the shoot in the tree crown. Circles indicate the level of lateral shoot on the mother shoot, and segments - the boundaries of shoots кроны. Так продолжается до стадии G1 и именно у виргинильных растений наблюдается максимум образования длинных побегов. С появлением генеративных органов быстрое развитие побегов тормозится, и количество длинных побегов относительно их общего числа уменьшается. Последующая фаза развития кроны характеризуется образованием большого количества мелких и средних побегов, причем количество первых постоянно возрастает.

Если представить целое дерево вариационными рядами его побегов по длине и количеству листьев, то после быстрого убывания в самом начале обе полученные кривые сразу же переходят в «длинный хвост» почти не меняющихся значений. При этом форма кривых мало зависит от условий произрастания дерева.

Под кривой продолжительности жизни макропобега относительно некоторой совокупности побегов будем понимать нормированный вариационный ряд побегов этой совокупности, рассматриваемый как функция количества междоузлий на них или их длин. На рисунке 7 изображены обе эти кривые для макропобега отдельно стоящего дерева $A$. negundo стадии G1 из базы данных ANTREES.

Большое количество сходных по размеру мелких побегов на дереве часто побуждало исследователей выбирать только их в качестве материала для работы (например, оценка влияния загрязнений, других внешних воздействий). Крупные же побеги, которых намного меньше, составляют скелет дерева и растут на его вершине. Их труднодоступность, незначительное количество на дереве, и важность для построения кроны приводит к тому, что при их удалении дерево сильно страдает и меняет форму кроны. Все это нередко становится причиной того, что их не включают в исследование.

Между тем, приспособление дерева к ухудшению внешних условий по-разному отражается на крупных и мелких побегах. Во-первых, происходит сокращение количества мелких побегов при незначительном уменьшении их размеров. Во-вторых, что проявляется намного ярче, происходит существенное сокращение как количества, так и размеров средних и длинных побегов.

Как было показано L. Maillette (1982) и B.F. Wilson (1989) исследование одних лишь почек и побегов дерева не позволяет восстановить его структуру. Необходимо учитывать свойства более крупных комплексов побегов. Это направление стало особенно бурно развиваться после выхода в свет книги F Halle и R.A.A. Oldemann (1970) об архитектуре строения растений. В России это направление получило развитие в работах Л.Е. Гацук (Gatsuk, 2008), 


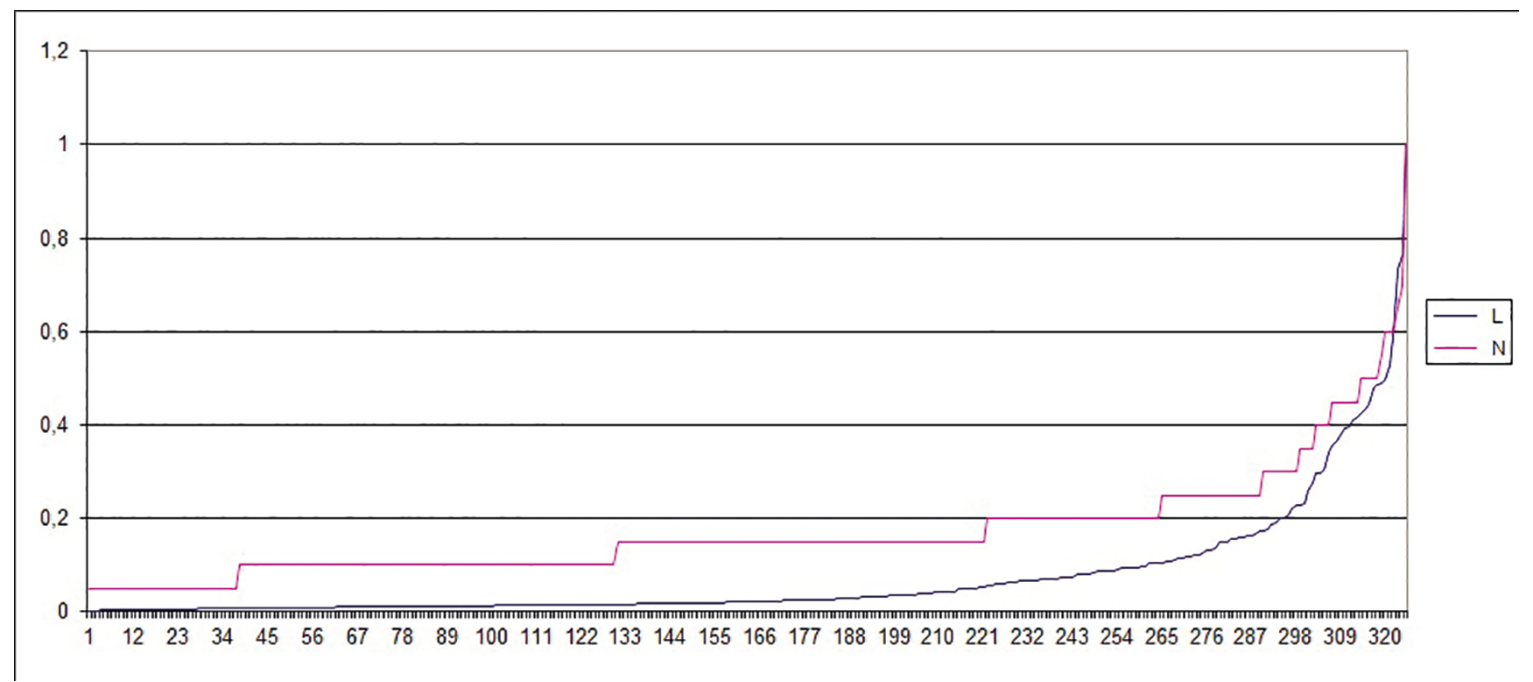

Рисунок.7. Нормированные кривые продолжительности жизни макропобега дерева $A$. negundo, построенные по количеству междоузлий $(\mathrm{N})$ и их длинам (L) для всех побегов дерева. По оси абсцисс меняется номер побега в вариационном ряду всех побегов дерева, по оси ординат - значения показателя N или L, нормированное на их максимальное значение

Figure. 7. Normalized curves of the lifetime of the macroshoot of the tree A. negundo, constructed from the number of internodes $(\mathrm{N})$ and their lengths (L) for all tree shoots. On the abscissa axis, the shoot number in the variational series of all tree shoots changes, along the ordinate axis - the values of $\mathrm{N}$ or L normalized to their maximum value

И.А Гетманец (Getmanets, 2008), М.Т. Мазуренко и А.П. Хохрякова (Mazurenko, Khokhryakov, 1991), Н.П. Савиных (Savinykh, 2012) и др.

В архитектуре дерева пространственно-временных единицы образуют четкую иерархию, каждый уровень которой существует в своем пространственном и временном масштабе. Взаимодействие всех уровней побеговых систем определяет развитие дерева. Основной пространственно-временной единицей является ДПС. На рисунке 8 показаны наиболее часто встречающиеся типы ДПС в кронах деревьев умеренной зоны на примере $A$. negundo.

Для сравнения ДПС «ростового» (Б), «основного» (В) и «заполняющего» типов на рисунке 8 приведены их графики изменения длин междоузлий на материнском побеге.

График длин междоузлий материнского побега ДПС на рисунке 9 дополнен изображением боковых побегов, развивающихся на материнском побеге в его верхних концевых междоузлиях.

В нижней части побега (зона I) вместо почек присутствуют только мелкие бугорки, затем в зоне быстрого увеличения длин междоузлий (II) закладываются только крайне мелкие (впоследствии спящие) почки. На плато кривой (III) развиваются мелкие почки, частично вырастающие в короткие боковые побеги. Нисходящая часть кривой (IV) несет основную часть боковых побегов.

В полной мере представленной зональностью обладают только материнские побеги самых развитых типов ДПС (А, Б на Рис. 8). В графиках междоузлий материнских побегов более мелких
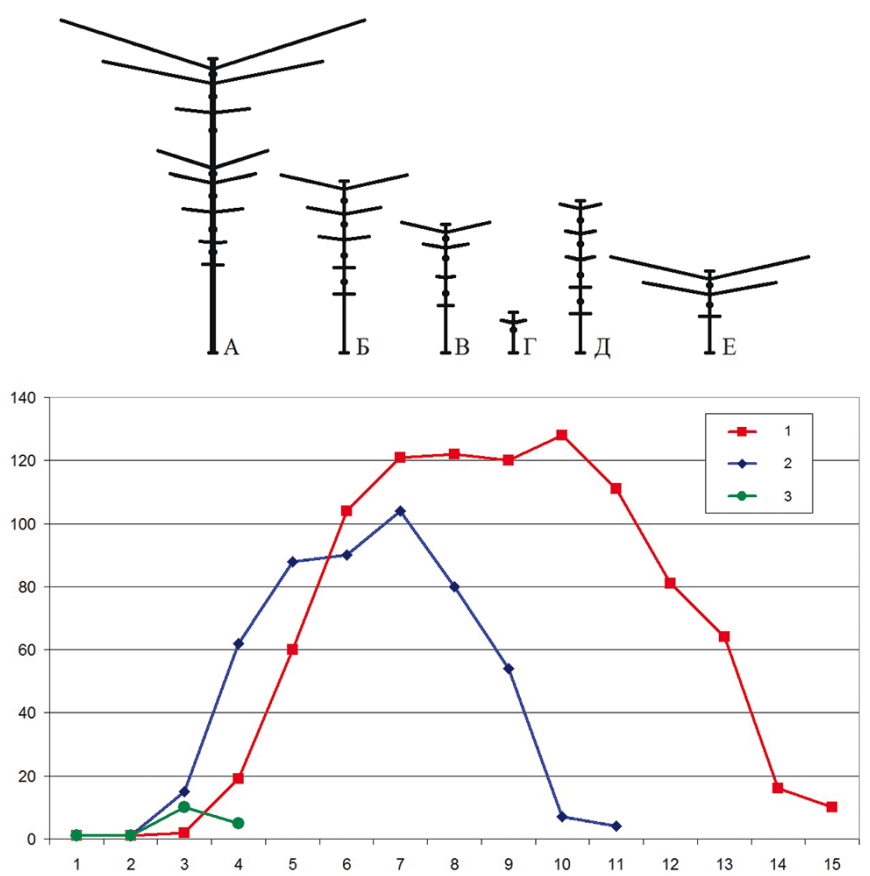

Рисунок 8. Типы ДПС $A$. negundo и диаграммы длин междоузлий типов Б (1), В (2) и Г (3).

По оси абсцисс меняется номер междоузлия от основания к верхушке, по оси ординат - длина междоузлия в мм

Figure 8. Types of BSS of $A$. negundo and diagrams of the lengths of internodes of types Б (1), B (2) and $\Gamma$ (3).

The number of internodes from the base to the top changes along the abscissa axis, along the ordinate axis - the length of the internode in $\mathrm{mm}$ 
типов ДПС сокращены, или полностью отсутствуют зоны II, III, IV.

Рисунок 10 схематически иллюстрирует предлагаемую нами параметрическую модель различных видов ДПС A. negundo в двух простых случаях.

Диаграмма длин междоузлий отражает только результат (траекторию в фазовом пространстве) процесса развития побега. По Н.П. Кренке (Krenke, 1940) его развитие происходит в двух разных шкалах времени.

Шкала длин междоузлий убывающей геометрической прогрессией разбивается на отрезки реальной и латентной стадий роста побега, следующие друг за другом. Для материнских побегов,

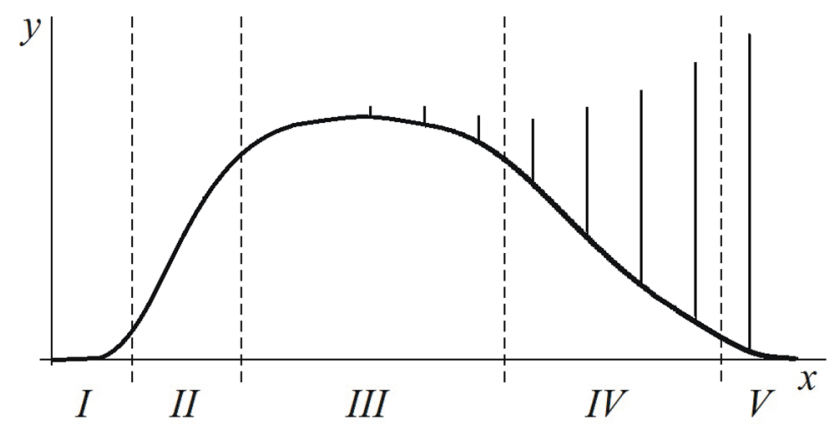

Рисунок 9. Схема расположения зон материнского побега «ростовой» ДПС A. negundo. Ось х - номера междоузлий от начала побега, у - длина междоузлий материнского побега. Пунктир соответствует границам зон (от I до V), а сплошные линии - длинам боковых побегов в соответствующих узлах материнского побега на второй год развития

Figure 9. Diagram of the zones of the mother shoot of the «growth» BSS of $A$. negundo. The x-axis - the internode numbers from the base of the shoot, $\mathrm{y}$ - the lengths of the internodes of the mother shoot. The dotted lines indicates boundaries of the zones (from I to V), and the solid lines the lengths of lateral shoots in the corresponding nodes of the mother shoot in the second year of development

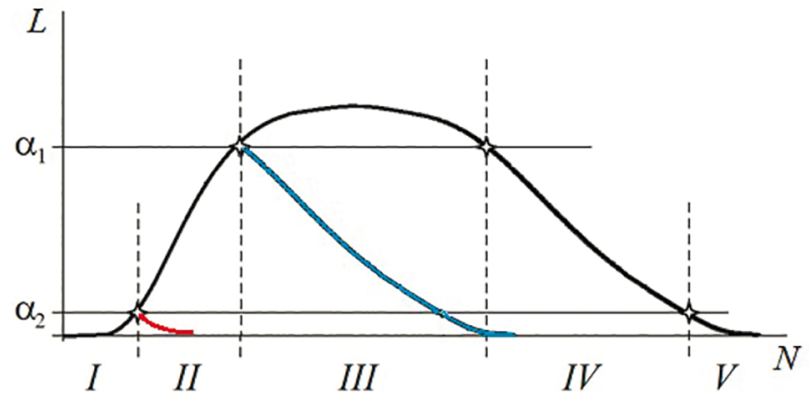

Рисунок 10. Схема моделирования побегов как недоразвитого материнского побега «ростовой ДПС»;

$\alpha 1$ и $\alpha 2-$ границы первых латентных интервалов материнских побегов «основной» и «заполняющей» ДПС. Ось $\mathrm{x}$ - номера междоузлий от начала побега, у - длины междоузлий материнского побега

Figure 10. Scheme of shoots modeling as an underdeveloped mother shoot of «growth BSS»; $\alpha 1$ and $\alpha 2$ - boundaries of the first latent intervals of the mother shoots of the «main» and «filling» BSS. The $\mathrm{x}$-axis - the internode numbers from the base of the shoot, $y$ - the lengths of the internodes of the mother shoot наиболее развитых ДПС нижняя граница первого латентного интервала достаточно высока. На рисунке 10 схематично изображены нижние границы первых латентных интервалов материнских побегов менее развитых типов ДПС: $\alpha_{1}-$ «основной» и $\alpha_{2}-$ «заполняющей». Так, в первом случае зона II сразу переходит в IV, а во втором зона I сразу переходит в V. Таким образом, различные типы ДПС оказываются недоразвившимися ДПС «ростового» типа. Модель выявляет огромное разнообразие форм «заполняющих» ДПС, которое нивелируется их малыми размерами. Выбор номера междоузлия от начала побега в качестве меры времени развития побега на кривой продолжительности жизни макропобега соответствует представлению о внутреннем онтогенетическом времени побега (Guedon et al., 2001). С точки зрения побега - это омоложение.

В качестве некоррелированных признаков, характеризующих динамику роста побега как КМНС процесса, были выбраны 2 признака: длины междоузлия и соответствующего максимального бокового побега на нем. Они были заменены на свои главные компоненты. По полученным факторам F1 и F2 в первых трех точках были построены оценки ковариационной функции процесса. Полученные оценки теоретической кривой $F$ для дерева $A$. negun$d o$ приведены в таблице 1.

На рисунке 11 представлен результат оценки кривой продолжительности жизни макропобега

Таблица 1. Оценки параметров кривой продолжительности жизни макропобега дерева A. negundo.

Table 1. Estimates of the parameters of the lifetime curve of the macroshoot of a tree A. negundo.

\begin{tabular}{ccccccc}
\hline$\tau$ & $\sigma^{2}$ & $\eta$ & $\mathrm{T}$ & $\mathrm{d}$ & $\mathrm{q}$ & Ткр \\
\hline 0,47 & 1,8824 & 1,319 & 13,37 & 11,5 & 0,000001 & 4,5
\end{tabular}

Примечание. $\tau$ - период задержки торможения роста макропобега (интенсивность омоложения), $1 / \sigma^{2}-$ нормирующий множитель до доли от нуля до единицы, $\eta$-интенсивность старения, Т - период роста в единицах времени (в междоузлиях), d - длина латентной стадии роста (в междоузлиях), q - максимальный параметр стратегии роста побега, Ткр - момент начала латентной стадии роста (в междоузлиях).

Note: $\tau$ - the retardation period of growth of the macroshoot (the intensity of rejuvenation), $1 / \sigma^{2}-$ the normalizing factor to a fraction from 0 to $1, \eta$ - the aging intensity, $\mathrm{T}-$ the period of growth in time units (in internodes), $\mathrm{d}$ - length of the latent stage of growth (in internodes), $\mathrm{q}$ - maximum parameter of shoot growth strategy, Ткр - the moment of the beginning of the latent stage of growth (in internodes). 
относительно целого дерева $A$. negundo по номерам междоузлий и оценка его теоретической кривой.

Для массива, составленного из побегов целого дерева молодой генеративной стадии (то есть макропобега), параметры, d и Ткр характеризуют продолжительность и начало латентной стадии старения макропобега этого дерева.

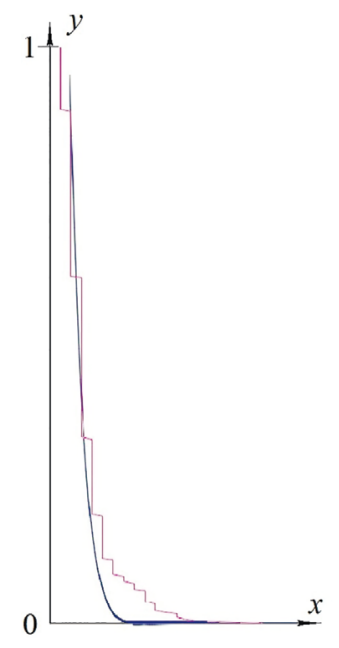

Рисунок 11. Совместный график кривой продолжительности жизни макропобега на дереве $A$. negundo по номерам междоузлий и оценка теоретической кривой

Figure 11. Joint graph of the lifetime curve of the macroshoot on $A$. negundo tree by internode numbers and estimate of the theoretical curve

Начало этого периода Ткр соответствует номеру междоузлия, который отделяет группу побегов с наименьшим количеством междоузлий. Такие побеги расположены, как правило, в нижней части крупных материнских побегов, эфемерны и несут листовую массу и генеративные органы. Их существовании управляется только материнским побегом породившей их ДПС.

Конец скрытой стадии, длина которой равна $\mathrm{d}$, соответствует номерам междоузлий на наиболее длинных побегах дерева.

Тскр $=$ Ткр $+\mathrm{d}=15,5$ (междоузлий $)$.

В таблице 1 параметр $q$ есть коэффициент подобия фрагментов теоретической кривой через период Т. Небольшое значение параметра говорит, прежде всего, об игнорировании моделью периодических смен стадий процесса (дроблении времени) в середине кривой жизни макропобега. Выделенная латентная фаза и по началу, и по длине довольно точно соответствует разнице между группами материнских побегов для «заполняющих» и «ростовых» ДПС.

Для массивов А и Б были также построены оценки параметров теоретической кривой продол- жительности жизни. В таблице 2 приведены характеристики массива Б ростовых ДПС.

Выборочным кривым продолжительности жизни массивов А и Б на теоретических кривых целого дерева U. glabra соответствуют ниспадающие участки А и Б.

Таблица 2. Оценки параметров кривой продолжительности жизни макропобега массива Б вида U. glabra.

Table 2. Estimates of the parameters of the lifetime curve of the macroshoot of array B of the form U. glabra.

\begin{tabular}{ccccccc}
\hline$\tau$ & $\sigma^{2}$ & $\eta$ & T & d & q & Ткр \\
\hline 1,217 & 1,9655 & 1,44 & 5,162 & 4,4 & 0,0006 & 4 \\
\hline $\begin{array}{l}\text { Обозначения соответствуют } \\
\text { correspond to table } 1 .\end{array}$ & таблице & 1. & Notations \\
& & & &
\end{tabular}

C учетом самоподобия ковариационной функции процесса кривые А и Б на рисунке после масштабирования должны соответствовать участкам А и Б теоретической кривой для всего дерева U. glabra (Рис. 12). На этом же рисунке мы можем увидеть неплохое согласие масштабированных кривых с реальными кривыми продолжительности жизни макропобегов для массивов А и Б, что говорит об адекватности модели в целом.

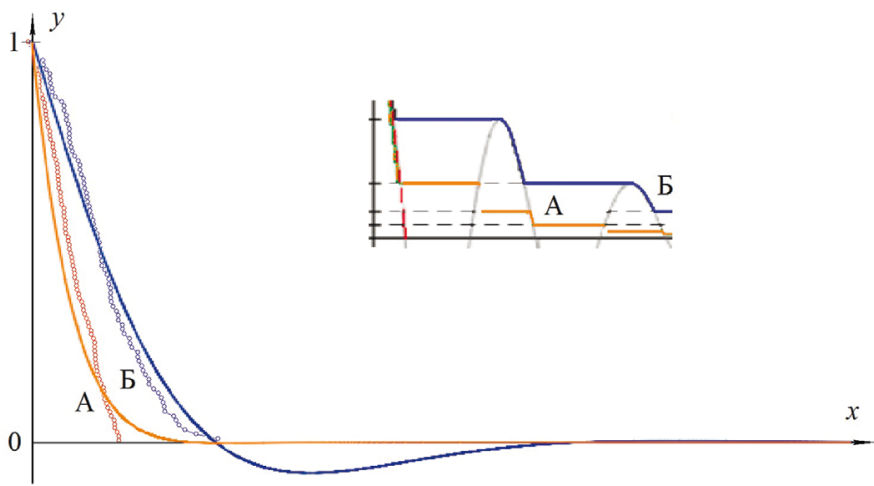

Рисунок 12. Совместные графики кривых продолжительности жизни макропобега по длинам побегов массивов А и Б деревьев U. glabra и оценки их теоретических кривых. Ось х - номера междоузлий; у - доля побегов, доросших (вероятность дорасти) до длины х

Figure 12. Joint graphs of the lifetime curves of a macroshoot along the lengths of shoots of arrays A and B of $U$. glabra trees and estimates of their theoretical curves. The $\mathrm{x}$-axis - the number of internodes; $\mathrm{y}$ - the proportion of shoots that have grown (the probability of growing) to the length of $x$ 


\section{В ы в о д ы}

Появление в исследовании многоуровневых биологических систем кривых типа времени жизни не случайно. Они представляют особый тип данных в статистике: значения имеют не пространственный, а временной смысл. При одновременном, с точки зрения наблюдателя, течении нескольких онтогенетических процессов структурных единиц кроны, сочетающиеся в одном онтогенезе структурной единицы более высокого уровня, исследователю не обойтись без неоднократного отражения (в нашем случае функционального обращения) пространственных характеристик во временные. При описании кроны как многоуровневой пространственно-временной структуры неизбежно сталкиваешься с переходом пространства во время и наоборот.

Сформулированы четыре важных биологических принципа, которые позволяют создать базу для построения моделей архитектуры кроны. Это принцип отражений, принцип основной программы развития структурной единицы, принцип задержки развития как единственной альтернативы смерти, и наконец, принцип зеркальности начала и конца ростапобега. Эти принципы прекрасно согласуются с многолетним опытом исследования роста и структуры крон деревьев и должны находиться в основе применяемого математического аппарата.

Введенная в работе кривая продолжительности жизни макропобега дерева отражает влияние различных пространственно-временных единиц кроны дерева на развитие побегов. Построенная модель позволяет выделить зоны макропобега (в номерах междоузлий) на основе его связи с дочерней ДПС.

Исследование поддержано грантом РФФИ, проект №16-04-01617.

\section{С п и сок лит е ратуры}

[Alekseeva] Алексеева Н.П. 2012. Анализ медико-биологических систем. Реципрокность, эргодичность, синонимия. СПб. 184 с.

[Antonova] Антонова И.С. 2008. О единицах морфологической структуры кроны древесных растений умеренной зоны. В кн.: Современные подходы к описанию структуры растения. Киров. С. 94-106.

[Antonova, Bart] Антонова И.С., Барт В.А. 2015. К вопросу о зональности побега на примере побегов Acer negundo L. Вестник ТвГУ. Сер. Биология и экология. № 4. С. 143-159.

[Antonova, Bart] Антонова И.С., Барт В.А. 2016. Анализ метрических характеристик двулетних побеговых систем Acer negundo L. в молодом генеративном состоянии. Вестник ТвГУ. Сер. Биология и экология. № 4. С. 151-159.
[Antonova] Антонова И.С., Барт В.А., Клочькова П.С. 2016. О строении побеговых систем некоторых видов рода Acer L. В сб.: XX Международная научнопрактическая конференция «Современные тенденции развития науки и технологий». № 11-1. С. 75-83.

[Antonova, Fatyanova] Антонова И.С., Фатьянова Е.В. 2016. О системе иерархических уровней строения кроны деревьев умеренной зоны. Бот. журн. Том 101. №. 6. С. 628-649.

[Antonova] Антонова И.С., Фатьянова Е. В., Зайцева Ю.В., Гниловская А.А. 2012. Мультимасштабность побеговых систем некоторых деревьев умеренной зоны (разнообразие, классификация, терминология). В сб.: Актуальные проблемы современной биоморфологии. Киров. С. 390-402.

[Arato] Арато М., Колмогоров А.Н., Синай Я.Г. 1962. Об оценке параметров комплексного стационарного гауссовского марковского процесса. Докл. АН СССР. Т. 146. № 4. С. 747-750

[Bart] Барт А.Г. 2003. Анализ медико-биологических систем. Метод частично обратных функций. СПб. 280 с.

Bart A.G., Klochkova N.P., Kozhanov V.M. 1993. The universal scheme of regulations in biosystems for the analysis of neuron junctions as an example. In: ModelOriented Data Analysis. Physica-Verlag. Heidelberg. 167-177 pp.

Costes E, Guédon Y. 2002. Modelling Branching Patterns on 1-year-old Trunks of Six Apple Cultivars. Annals of Botany. 89(5): 513-524. https://doi.org/10.1093/aob/ mcf078

[Dynkin] Дынкин Е.Б. 1963. Марковские процессы. M. 860 c.

[Gavrikov, Khlebopros] Гавриков В.Л., Хлебопрос Р.Г. 2013. Феноменологическая модель управления углеродным лесом. Лесоведение. № 5. С. 29-35.

[Galitskii] Галицкий В.В. 2004. Квази-трехмерная модель свободно растущего дерева. Электронный журнал. Исследовано в России. № 247. С. 2646-2662. http://zhurnal.ape.relarn.ru/articles/2004/247.pdf.

Galitskii V.V. 2013. Biomass Dynamics of HigherOrder Tree Branches: An Analysis of the Model. Biology Bulletin Reviews. 3(5): 412-421. https://doi. org/10.1134/s2079086413050034

[Gatsuk] Гацук Л.Е. 2008. Растительный организм: опыт построения иерархической системы его структурно-биологических единиц. В сб.: Современные подходы к описанию структуры растения. Киров. C. $27-47$.

[Getmanets] Гетманец И.А. 2008. Подходы к анализу биоморф видов рода Salix (на примере ив Южного Урала). В сб.: Современные подходы к описанию структуры растения. Киров. С. 106-115.

[Grudzinskaya] Грудзинская И.А. 1960. Летнее побегообразование у древесных растений и его классификация. Бот. журн. Т. 45. № 7. С. 968-978.

Guédon Y, Barthélémy D, Caraglio Y, Costes E. 2001. Pattern analysis in branching and axillary flowering sequences. Journal of Theoretical Biology. 212(4): 481520. https://doi.org/10.1006/jtbi.2001.2392 
Hallé F., Oldemann R.A.A. 1970. Essai sur l'architecture et la dynamique de croissance des arbres tropicaux. Paris. 178 pp.

[Feller] Феллер В. 1984. Введение в теорию вероятностей и её приложения. Т. 2. М. 738 с.

Fisher R.A. 1956. Statistical Methods and Scientific Inference. New York.

[Krenke] Кренке Н.П. 1940. Теория циклического старения и омоложения растений и практическое ее применение. Сборник статей. М. 135 с.

Lee T.D., Yang C.N. 1956. Question of parity conservation in weak interactions. Phys. Rev. 104: 254-258.

Maillette L. 1982. Structural dynamics at silver birch. I. The fates of buds. J. Appl. Ecol. 19(1): 203-218.

[Mazurenko, Khokhryakov] Мазуренко М.Т., Хохряков А.П. 1991. Классы метамеров деревьев. Журн. общ. биол. Т. 52. № 3. С. 409-421.
[Novozhilov] Новожилов Ю.В. 1972. Введение в теорию элементарных частиц. М. 472 с.

Prusinkiewicz P., Lindenmayer A. 2012. The Algorithmic Beauty of Plants. Springer Science \& Business Media. $228 \mathrm{p}$.

[Savinykh] Савиных Н.П. 2012. Архитектура трав. В сб.: Актуальные проблемы современной биоморфологии. Киров. С. 342-354.

[Shitt, Metlitskii] Шитт П.Г., Метлицкий 3.А. 1940. Плодоводство. М. 660 с.

Wilson B.F. 1989. Tree branches as populations of twigs. Canad. J. Bot. 67(2): 434-442.

Wilson B.F. 1992. Compensatory growth in shoot populations of young white pine trees. Trees: Structure and Function. 6(4): 204-209. 


\title{
Structure of crowns of woody plants of temperate zone of Acer negundo and Ulmus glabra as an example
}

\author{
(C) I.S. Antonova , V.A. Bart \\ Saint-Petersburg state University, Saint-Petersburg, Russia \\ e-mail:ulmaceae@mail.ru
}

\begin{abstract}
The tree crowns of Acer negundo and Ulmus glabra, were investigated in different age states and in different points of the areal. The model of zonality of shoot based on the relationships between development processes of shoot and other space-time structural units of the crown (biennial shoot systems, epsion, etc.) is suggested. Developmental delay (latent stage) is considered to be an alternative of aging process of shoot. The model uses the mathematical apparatus of partial inverse functions, estimation of parameters of covariance function of complex normal stationary Markovian process by its multidimensional trajectories.
\end{abstract}

Keywords : crown, shoot systems, shoot zonality, reflection principle, partial inverse functions.

\section{References}

Alekseeva N.P. 2012. Analiz medico-biologicheskikh system. Petsiproknost, ergodichnost, sinonimiya [Analysis of medical and biological systems. Reciprocity, ergodicity, synonymy]. Saint-Petersburg. 184 pp. (In Russ.)

Antonova I.S. 2008. O edinitsakh morfologicheskoi struktury krony drevesnykh rasyenii umerennoi zony [On the units of the morphological structure of the crowns of woody temperate plants]. In: Sovremennyye podkhody $k$ opisaniyu struktury rasteniya [Modern approaches to describing the structure of plants]. Kirov. 94-106 pp. (In Russ.)

Antonova I.S., Bart V.A. 2015. K voprosu o zonalnosti pobega na primere pobegov Acer negundo L. [To the question of the zoning of the shoot by the example of shoots Acer negundo L.]. Vestnik Tverskogo gosudarstvennogo universiteta. Seriya Biologiya i ekologiya. 4: 143-159. (In Russ.)

Antonova I.S., Bart V.A. 2016. Analiz metricheskikh kharakteristik dvuletnikh pobegovykh system Acer negundo L. v molodom generativnom sostoyanii [Analysis of the metric characteristics of the biennial shoot systems of Acer negundo L. in the young generative state]. Vestnik Tverskogo gosudarstvennogo universiteta. Seriya Biologiya i ekologiya. 4: 151-159. (In Russ.)

Antonova I.S., Bart V.A., Klochkova P.S. 2016. O stroenii pobegovykh system nekotorykh vidov roda Acer L. [On the structure of shoot systems of some species of the genus Acer L.]. In: XX Mezhdunarodnaya nauchno-prakticheskaya konferentsiya "Sovremennyye tendentsii razvitiya nauki i technologii” "[International scientific-practical conference "Modern trends in the development of science and technology"]. Vol. 11-1. 75-83 pp. (In Russ.)

Antonova I.S., Fatyanova E.V. 2016. O sisteme ierarkhicheskikh urovnei stroeniya krony derevev umerennoi zony [About system of hierarchical levels of a structure of a crown of trees of a temperate zone. Botanicheskii zhurnal. 101(6): 628-649. (In Russ.)

Antonova I.S. Fatyanova E.V., Zaitseva Yu.V., Gnilovskaya A.A. 2012. Multimasshtabnost pobegovylh system nekotorykh derevev umerennoi zony (raznoobraziye, klassifikatsiya, terminologiya) [Multiscale shoot systems of some temperate trees (diversity, classification, terminology)]. In.: Aktualnyye problemy sovremennoi biomorfologii [Actual problems of modern biomorphology]. Kirov. 390-402 pp. (In Russ.)
Arato M., Kolmogorov A.N., Sinai Ya.G. 1962. Ob otsenke parametrov kompleksnogo statsionarnogo gaussovskogo markovskogo protsessa [On the estimation of the parameters of a complex stationary Gaussian Markovian process]. Doklady AN SSSR. 146(4): 747-750.

Bart A.G. 2003. Analiz medico-biologicheskikh system. Metod chastichno obratnykh funktsii [Analysis of medical and biological systems. Method of partially inverse functions]. Saint-Petersburg. 280 pp. (In Russ.)

Bart A.G., Klochkova N.P., Kozhanov V.M. 1993. The universal scheme of regulations in biosystems for the analysis of neuron junctions as an example. In: Model-Oriented Data Analysis. Physica-Verlag. Heidelberg. 167-177 pp.

Costes E, Guédon Y. 2002. Modelling Branching Patterns on 1-year-old Trunks of Six Apple Cultivars. Annals of Botany. 89(5): 513-524. https://doi.org/10.1093/aob/ $\operatorname{mcf078}$

Dynkin E.B. 1963. Markovskiye protsessy [Markovian processes]. Moskow. 860 pp. (In Russ.)

Feller V. 1984. Vvedeniye $v$ teoriyu veroyatnostei $i$ eye prilozheniya [Introduction to probability theory and its applications]. Vol. 2. Moscow. 738 pp. (In Russ.)

Fisher R.A. 1956. Statistical Methods and Scientific Inference. New York.

Galitskii V.V. 2004. Kvazi-trekhmernaya modekm svobodno rastushchego dereva [Quasi-three-dimensional model of a freely growing tree]. Electronnyi zhurnal. Issledovano $v$ Rossii. [Electronic Journal. It is investigated in Russia]. 247: 2646-2662. (In Russ.) Available at: http://zhurnal.ape.relarn.ru/articles/2004/247.pdf.

Galitskii V.V. 2013. Biomass Dynamics of Higher-Order Tree Branches: An Analysis of the Model. Biology Bulletin Reviews. 3(5): 412-421. https://doi.org/10.1134/ s2079086413050034

Gatsuk L.E. 2008. Rastitelnyi organism: opyt postroeniya ierarkhicheskoi sistemy ego strukturno-biologicheskikh edinits [Plant organism: the experience of constructing a hierarchical system of its structural and biological units]. In: Sovremennyye podkhody k opisaniyu struktury rasteniya [Modern approaches to describing the plant structure]. Kirov. 27-47 pp. (In Russ.) 
Gavrikov V.L., Khlebopros R.G. 2013. Fenomenologicheskaya model upravleniya uglerodnym lesom [Phenomenological model of carbon forest management]. Lesovedeniye. 5: 29-35. (In Russ.)

Getmanets I.A. 2008. Podkhody k analizu biomorf vidov roda Salix (na primere iv Yuzhnogo Urala) [Approaches to the analysis of biomorphs of Salix (by the exam$\mathrm{pl}$ of willows in the South Urals). In: Sovremennyye podkhody $k$ opisaniyu struktury rasteniya [Modern approaches to describing the plant structure]. Kirov. 106-115 pp. (In Russ.)

Grudzinskaya I.A. 1960. Letneye pobegoobrazovaniye u drevesnykh rastenii i ego klassifikatsiya [Summer shoots in woody plants and its classification]. Botanicheskii zhurnal. 45(7): 968-978. (In Russ.)

Guédon Y, Barthélémy D, Caraglio Y, Costes E. 2001. Pattern analysis in branching and axillary flowering sequences. Journal of theoretical biology. 212(4): 481- 520. https://doi.org/10.1006/jtbi.2001.2392

Hallé F., Oldemann R.A.A. 1970. Essai sur l'architecture et la dynamique de croissance des arbres tropicaux. Paris. $178 \mathrm{pp}$.

Krenke N.P. 1940. Teoriya tsiklicheskogo stareniya $i$ omolozheniya rastenii $i$ prakticheskoye ee primeneniye. Sbornik statei [The theory of cyclic aging and rejuvenation of plants and its practical application. Digest of articles]. Moscow. 135 pp. (In Russ.)
Lee T.D., Yang C.N. 1956. Question of parity conservation in weak interactions. Phys. Rev. 104: 254-258.

Maillette L. 1982. Structural dynamics at silver birch. I. The fates of buds. J. Appl. Ecol. 19(1): 203-218.

Mazurenko M.T., Khokhryakov A.P. 1991. Klassy metamerov derevev [Classes of metamers of trees]. Zhurnal obshchei biologii. 52(3): 409-421. (In Russ.)

Novozhilov Yu.V. 1972. Vvedeniye $v$ teoriyu elementarnykh chastits [Introduction to the theory of elementary corpuscles]. Moscow. 472 pp. (In Russ.)

Prusinkiewicz P., Lindenmayer A. 2012. The Algorithmic Beauty of Plants. Springer Science \& Business Media. $228 \mathrm{p}$.

Savinykh N.P. 2012. Arkhitektura trav [Architecture of herbs]. In: Aktualnyye problemy sovremennoi biomorfologii [Actual problems of modern biomorphology]. Kirov. 342354 pp. (In Russ.)

Shitt P.G., Metlitskii Z.A. 1940. Plodovodstvo [Fruit-growing]. Moscow. 660 pp. (In Russ.)

Wilson B.F. 1989. Tree branches as populations of twigs. Canad. J. Bot. 67(2): 434-442.

Wilson B.F. 1992. Compensatory growth in shoot populations of young white pine trees. Trees: Structure and Function. 6(4): 204-209. 